\title{
PARA QUE SERVE O NOME QUE CARREGO, QUANDO MINHAS CULTURAS SE DESMANCHAM?*
}

\author{
Olivier Douville
}

Psicanalista;

membro do

Laboratório CRPMS,

Universidade de

Paris 7; membro da

Associação Francesa

de Antropólogos;

autor de De

l'adolescence errante

(Nantes: Plein

Feux, 2008, Prêmio

Oedipe de 2008).

Tradução

Pedro Henrique Bernardes

Rondon

Psicanalista;

membro efetivo

da Sociedade de

Psicanálise da

Cidade do Rio de

Janeiro (SPCRJ);

membro efetivo

da Associação

Brasileira para o

Estudo da Psicologia

Psicanalítica do Self

(Abepps).

RESUMO: O exercício contemporâneo da psicanálise com sujeitos que estão às voltas com a história revela os importantes efeitos da destruição das subjetividades nos contextos sociais e políticos marcados pela recusa de alteridade, por exclusões e segregações. O valor simbólico e o lugar significante do nome próprio são atacados aí, e o nome pode se ver reduzido a uma objetalidade.

Palavras-chave: exclusão, exílio, melancolização do laço social, nome próprio, segregação.

ABSTRACT: What is the reason for the name I bear, when my cultures crumble?. The contemporary exercise of psychoanalysis with subjects that are at odds with history reveals the important effects of the destruction of the subjectivities in social and political contexts marked by the refusal of otherness, by exclusions and segregations. The symbolic value and the significant place of one's own name are attacked there, and the name may find itself reduced to an object.

Keywords: exclusion, exile, melancolization of the social bond, one's own name, segregation.

* Este artigo é dedicado ao músico de jazz Teddy Bunn, in memoriam. 
E m que condição se cria para um sujeito um saber acerca da origem, e de que maneira esse saber interroga os significantes da filiação?

Aqui a clínica não é cultural ou culturalista. Pressupõe que não se leve em conta a dimensão social, o laço.

Vou partir disto: a psicanálise não vai reduzir quem quer que seja às suas particularidades culturais. Um tratamento pode permitir ao sujeito uma relação de descrença com essas particularidades a partir do momento em que ele reconheça que sua particularidade mais “íntima” pode, assim como uma luva que se vira do avesso, se alojar e se reencontrar no mais universal. A questão do ponto de origem se desloca e se divide até aparecer também em seu bordo externo de ficção. Na situação analítica, uma palavra reúne o vestígio, dando-lhe esse estatuto particular de origem descoberta ainda que criada, situada no "espaço intermediário”. A origem então não é mais um princípio de causalidade fatal, que exige a repetição sem reconstrução. Atravessada em direção a uma sublimação, e não retorno ao mesmo, a fim de que a palavra visite novamente as fímbrias do trauma e se afaste das seduções arcaicas.

Por isso é possível dizer que o pensamento psicanalítico acerca da condição institucional do humano no corpo e na linguagem é, em sua essência, uma teoria daquilo que possibilita um laço social, e que é na confrontação com a realidade histórica e política que a psicanálise conhece o seu transbordamento.

O que será daqueles cujas modalidades de travessia dos campos, e dos laços sociais que tomaram emprestados, reduziram a sucata o corpo e o nome? O que será daqueles que perderam a esperança nos poderes da palavra? O que será, enfim, da possível esperança nesses poderes da palavra em sociedades marcadas pelo culto da eficácia e da política da segregação? Há formas particulares de rupturas que causam vivo sofrimento, ou põem em perigo o fato de se carregar um nome. O exílio, mas também determinadas explosões de desligamento no extremo isolamento dão a medida disso. A destruição do Nome é, talvez, o signo desses desvios simbólicos que trabalham nosso laço social.

A questão que atravessa este texto estará situada entre a experiência clínica psicanalítica e os fenômenos de ligação e de desligamento que se observam no social. Como exibição da angústia da não-nomeação, há fantasias de autoengendramento que, algumas vezes, não são mais do que lembranças encobridoras de um assassinato do nome. Como ler a origem, como dotar a si mesmo de paradigmas representativos da genealogia? A possibilidade de narração, ou seja, o trabalho de um mito individual, torna a acomodar e a dirigir essas palavras que, por terem perdido a nomeação e a residência, se repetem como metonímias sem direção, amputadas de um lugar onde poderiam se modificar e se transmitir.

Decerto o inconsciente não é intrapsíquico, mas sim interpsíquico. É esse aspecto que distingue a psicanálise de qualquer outra psicologia. Parece-me cada 
vez mais que o estudo das consequências do desmoronamento repentino dos significantes de uma cultura é mais proveitoso para a conceituação psicanalítica do laço social do que uma referência etnológica sempre saturada de noções como as de aculturação ou de "inconsciente étnico".

O enigma universal é o do desejo do homem de ficar endividado por uma palavra viva. Deduz-se daí que o humano vai endossar esse enigma por sua sujeição estruturante a uma encenação da vida transgeracional e transindividual da palavra.

Se a ordem do inconsciente se revela heterogênea ao sujeito, uma vez que o sujeito se subjetiva e toma corpo na diferença significante (ainda estando, no plano do fantasma, ligado ao resto dessas operações - resto dito objeto perdido), e que o inconsciente desconhece a contradição, o social vai se definir pelo laço que garante ou não a possibilidade de sobrevivência e de transmissão do registro da palavra de uma geração para a outra. Passa entre as gerações, se seguirmos as ficções freudianas, a arte de recolher os afetos do fracasso, de miséria, da angústia.

Mas também, os choques de culturas, as guerras de culturas, os ódios das outras metáforas da ancestralidade (aquilo que, por comodidade, os psicanalistas durkheimianos chamam de “Pai”). Aspecto do moderno que se precipita no universo absoluto das leis de mercado, isso implica a colocação entre parênteses de todas as paixões humanizantes, de todas aquelas que refreiam o aspecto superpoderoso do mundo material. A queda das alteridades e a recuperação dessas alteridades na fetichização odienta do estrangeiro exótico e indesejável têm uma consequência imediata: o valor pulsional daquilo que volta do exterior vai se encontrar extrema e inteiramente realçado, no temor ou no pânico de gozo. O cálculo da segregação logo vai adquirir valor defensivo e, à medida que protege essa perigosa ficção do justo direito ao conveniente do gozo, deixa o majoritário intacto, inocente, desculpado de ter que propor a si mesmo a questão do seu desejo.

Diante disso, como vai ser, para um sujeito apanhado nessa tormenta, pensar o destino de suas pegadas num mundo em que se destrói a morada do Nome, em que se desmente o pensamento genealógico? Àquele que está preso ao esmagamento de qualquer posição subjetiva ocorre sobreviver, quando a injunção amável posto que federativa, é voltar numa inclusão dada para o lugar de partida. O efeito dessa injunção é o crescimento daqueles que se encontram relegados, sem retorno. Autóctone encerrado, exilado privado de lugar — duas figuras radicais do sem-lugar quando é reconduzido, e arruinado no "espaço intermediário". Fabricação assassina de sujeitos sacrificados ao fora-do-discurso, de sujeitos votados para o discurso que nunca mais seria da ordem do semblante. 
Hoje em dia, nosso tempo de promoção de guerras e felicidades industriais se paga com o desmoronamento das metáforas, isto é, pelo assassinato da distância entre a palavra que evoca e invoca, e a coisa. Nesse desencadeamento, mórbido e melancólico, do princípio de indiferença generalizada (forma doentia do princípio de prazer), como a introdução de um elemento estrangeiro poderia provocar novas construções e novas interpretações? Um social que se esforça para reduzir à insignificância a diferença entre a vida e a morte não pode suportar dentro dele o heterogêneo e o estrangeiro. Cuidamos das modalidades específicas e codificadas de seu gozo, modalidades tolamente denominadas 'identidades' — talvez mesmo identidades culturais — por muitos, dentre os quais, em nossos campos “científicos”, os novos promotores de guetos — os etnopsicanalistas franceses.

Daí, uma proposição: o estudo clínico dos modos de vida da palavra (e de prejuízo dessa vida) é estudo dos poderes da palavra, a ser colocado em deslocamento e transferência, isto é, também em sintoma e em desejo. Potência de acolhimento daquilo que perturba o que é familiar.

A reflexão sobre a comunidade leva a pensar na hipótese de uma melancolização do laço social, no momento em que as respostas de fora impedem nos grupos a possibilidade de um pensamento de troca e de acolhimento.

Qualquer que seja o tipo de sociedade, não há cultura e laço social sem violência. A subjetivação, processo que vai fazer do vivente um sujeito, não fica bem sem uma prescrição de renúncia ao gozo (eis aí um lugar-comum), nem sem colocar esse sujeito numa ilusão comunitária de memória compartilhada. Donde certa separação entre verdade e ilusão, entre memória tradicional e memória pura da pura pulsão de morte, entre engendramento e engolfamento, chamada da ameaça aquilo que poderia nunca ter sido.

Pensar assim é também pensar a cultura de um modo diferente, e não em termos de enquadramento, para defini-la como um poder coletivo de resistência contra o trabalho de erosão do significante, como um poder de fazer os sonhos partilhados e os lugares fecundos voltarem a florir, dentre eles o "lugar do estrangeiro" (conforme a poderosa expressão de P. Fedida) não é o menor dos bens de civilização a serem conservados, nestes tempos em que as conquistas tecnológicas conduzem para o abstrato, um achatamento dos modos de gozar e do visível.

A catástrofe subjetiva se acentua quando a violência fica sem narrativa, clandestina e secreta, ao ponto de que falar dela volta a tocar no tabu dos mortos.

As feridas da história. As monstruosidades assassinas do simbólico e do laço, o sujeito não tem mais o controle, ele está na condição de presa de uma sideração quando seu corpo e seu nome não valem nada diante da ameaça, quando não lhe resta mais um sopro, nem mais uma migalha de vida para oferecer seu rosto 
como lugar onde se reflete o interdito do assassinato. Assassinato da morte, na morte em massa. Esmagamento da genealogia. Identidades errantes de mortosvivos no meio dos vivos-mortos impassíveis da compacta maioria.

Na desintegração do Nome próprio, é então o valor pulsional que se libera, esvaziando, mais do que despedaçando, o corpo simbólico. Esvaziando esse corpo simbólico que torna plausível um corpo vivo, em suma, o pacto entre Nome e Corpo. É o caso exemplar desses operários, que muitas vezes são magrebinos que, após um acidente de trabalho - acidente que na maioria das vezes é provocado por deslocamentos de corpos ou de objetos — rompem todo elo possível com a outra terra, a outra margem, e que só se apresentam levando com eles (ou contra eles) pastas de especialistas em que, no amontoado sem sentido das avaliações de prejuízos, seu nome não se torna mais aquele traço absurdo que circula sem eles, que é discutido sem eles. O escrito é separado da voz. Puro achatamento da pulsão escópica, nada dá lugar ou direção dentro e fora do corpo. É sempre o cheio demais de imagem a que ele se encontra reduzido e que reflui sobre o sujeito quando ele não está mais protegido pelo valor simbólico de seu nome.

Nunca se dirá a que ponto o assassinato do nome se reproduz quando o dizer e o fazer reconhecer seu nome se resumem a dizer e fazer reconhecer o aspecto de estar tudo correto quanto aos papéis nos quais o nome está escrito. O Nome que o clandestino, o sem-documentos, carrega, não é mais do que um signo, um sinal que garante a entrada, ou que o precipita em direção à saída. É o Nome em Estado Limite, nos limites do Estado... Escrita sempre carregada de suspeitas para aqueles que sem descanso controlam, escrita que sempre expropria o ser daquele a quem só resta essa única marca, seu nome sem sombra, escrito como um número, para circular em terra estrangeira. É nesse momento de brutal transformação do nome em espectro, que o mundo - que segundo Lacan existe entre a palavra e a letra — num turbilhão, engole e cospe. Um nome à deriva, sem nome nem pai substituto. Um nome que é tomado como nada que valha a pena, como algo comum, um corpo fantoche é apropriado ao sujeito pelos outros.

O drama aqui não é que o corpo se torne uma alteridade para o sujeito, posto que é isso que faz o sujeito, mas sim que essa alteridade de corpo não seja socialmente percebida em sua dignidade de corpo.

Vamos até dizer a palavra: o racismo, conhecido conjuntamente sob o primado de um unário insultando o eu ao corpo, inextricavelmente, na caricatura violenta que se considera saber antropológico, donde a intercambiabilidade que o pensamento racista dá ao estrangeiro, o “eles são todos assim”, seja o fetichismo da pequena diferença tida como marca de massa.

Ora, a questão do lugar da crueldade que segrega no laço não é fatal. Ela reclama se se quer enfrentá-la, não uma condenação fóbica do moderno, mas 
um pensamento político, um pensamento do direito de cidadania da alteridade necessária, a ser ganho sobre a paixão da amnésia, sobre a tentação do desconhecimento. Resistir ao amor por essa face temível do Outro inconsciente que manda acreditar numa promessa do gozo total e indivisível. Esse gênero de promessa é o que o social produz na moderna injunção a recusar as representações e as formas institucionais da discriminação. Consentir em dar corpo a essa injunção torna a violentar o genealógico, isto é, a razão e a justiça genealógica. Repetição lasciva das facilidades consumistas afetando a capacidade de aparecer dada ao acontecimento.

Se tudo é equivalente, tudo pode ser recusável e intercambiável, até mesmo e inclusive o Nome que se carrega e que nos carrega.

É verdade que dar e receber um nome próprio, um nome limpo, ${ }^{1}$ é diferente de ser designado como particularidade, e dentro de sua particularidade. Há no Nome Próprio algo insubstituível, posto que há a alteridade indivisível que aparece e recolhe a epopeia de uma memória imemorial. Há um Nome próprio quando alguma coisa de um elo se estabelece entre uma voz e uma letra, quando uma afinidade está em jogo entre um eu, um corpo e o dom de uma letra que não vem de lugar nenhum. Intraduzível, exceto quanto a fazer dele quase um insulto ou uma ridicularia frágil e fragilizante, o nome, em razão de sua amarra literal, é dotado para a viagem, e talvez mesmo seja aplicado exclusivamente à viagem, posto que não são somente os homens que migram, mas também as palavras e as letras se deslocam e se transferem. Ora, o que acontece quando o cordão umbilical do nome, impossível de cortar (que é preciso distinguir radicalmente de sua compacta objetalização vivida por certos exilados) busca seu acolhimento, senão que ele vem alojar-se de um modo um pouco diferente, ou vem desalojar de um modo um pouco diferente, a montagem ficcional de uma compacta maioria - mais uma vez essa preciosa expressão freudiana - no corpo-fetiche de um Mestre.

A escrita, é verdade, nasce com a negação. O efeito da análise não é consolidar um nome, mas também não é fazer dele um fetiche ou um sarcófago de pais mortos demais, para deixar os filhos em paz. O efeito da análise é permitir que o sujeito possa dizer seu nome sem ter outras contas a prestar senão à lei simbólica: aquela que diz que é preciso partir de um nome para fazer um trajeto, para passar de uma casa para outra, passagens cumpridas de modo que o brilho e o sopro da letra retornem sobre o sujeito, mas não para identificá-lo ou localizá-lo, não para capturá-lo. A diferença entre o esquecimento do Nome e o assassinato do Nome é que o esquecimento permite um faz-de-conta de substituição, em que algumas figuras da letra se desenham na borda, em sonho e em sintoma.

\footnotetext{
${ }^{1}$ Há no original um jogo de palavras: "un nom propre, un nom en propre”. (N. do T.)
} 
No assassinato do nome, nesse assassinato em que o sujeito não é nada mais do que a pobre coisa intercambiável que o nome estigmatizado se tornou, é toda a montagem do sujeito, ao pé da letra, que se encontra abolida. A ausência da letra abre um abismo. A dignidade da demanda não é mais deste mundo.

Não é então uma falha que se desenha no corpo do Outro, mas uma diluição desse outro que somente a clivagem pode então salvar, porque toda demanda pode tornar-se fatalmente perigosa, expondo à ameaça de uma metamorfose de si fora das ilusões do humano. Quando é reduzido a sucata, então o nome não se transfere mais.

É muitas vezes no achatamento de uma palavra que não pode ter acesso à amnésia e ao simulacro, quando a dor de existir não é retomada no surgimento de uma polaridade qualquer reivindicadora ou agressiva, que determinados pacientes poderiam dizer "fui sacrificado". Sacrificado à história familiar ou social, à cultura do pai ou da mãe, da origem ou da residência... Nas palavras deles, essa causa é recoberta pelo verdadeiro. Pela suposição do Verdadeiro e do Real, a pulsão, seu objeto e o Eu se confundem e o corpo, despovoado das letras que o amarram ao literal dos enunciados coletivos, se torna esse fato compacto, encravado na experiência lânguida de uma vivência de sobrecarga. A exclusão é extrema, a compulsão desvia tudo.

Esses exilados, duplicando seu exílio, aqueles que deixaram um país para acabar encontrando uma ausência radical de país, não encontraram o lugar de seu semblante, nem o lugar de seu combate. Eles são errantes. E não é sem riscos quando, na condição de errante sem profundidade de campo, sem borda, sobrevém a injunção de que seja preciso haver uma ruína ou uma morte real no outro, por não poder negociar na palavra, na interlíngua, uma morte simbólica do outro.

Se todo o nosso aparato para dirigir uma cura exige uma "revisão" dos dogmas e dos temas canônicos quanto à cura do neurótico, é também à medida que a origem traumática se desloca na cura, com seus efeitos tensos de transferência (estando arruinado o espaço intermediário, certos pacientes, superando a apatia melancólica, nos deixam ouvir que na cura como na vida é ou eles ou eu... o que é desafiador, mas é bom sinal). Como pensar essa passagem subjetiva que vai da exclusão (com essa colagem mortífera à exceção no abandono de tudo) à solidão?

Hoje, temos também que pensar diferentemente a economia de gozo não das multidões, mas das massas; dito de outro modo, a economia libidinal das configurações de gozo das massas apaixonadas pelo fetiche de sua unidade escópica. E vemos bem de que maneira prolifera o risco de fora-do-discurso no laço, e nas margens desse laço, risco realizado atualmente pelo sacrifício de homens e mulheres banidos dos lugares manifestos da subjetivação. A ditadura 
pós-moderna faz proliferar as experiências de forclusão desse território sem território que é o lugar da palavra.

Fabricação maciça do sujeito “descartável” num mundo cada vez mais estéril, cada vez menos inclinado a aceitar que a sexualidade, assim como a história, sejam montagens destinadas a criar diferença.

O quanto as culturas não são mais do que virtuais, o quanto são levadas à catástrofe nos recursos figurais de suas línguas, então, o que se preconiza de laço vem para garantir que seja permitido desfrutar novamente dessa ficção totalitária da inocência, do direito infalível ao solo, a querer novamente sobrepor isso ao assassinato (vulgarmente confundido com o sacrifício, nesse momento em que o assassinato é a morte realizada sobre o outro e do Outro, sem espaço de interpretação). Seja para o sujeito consentir na incitação a se entregar a uma ficção que transborda pelo ato, uma identidade amável pela destruição do outro em sua humanidade, e além de sua humanidade. Ideologia embrionária, imperativa e impulso ao crime. Essa ideologia entregue ao âmago de sua violência se gaba de seu justo direito a esquecer que não é o assassinato que origina o simbólico. O assassinato convoca o simbólico, a destruição não interpretada não desemboca diretamente na simbolização ou na separação. Pode-se matar para não abandonar, muitas vezes se mata para não separar, para não se tornar estrangeiro de si mesmo.

A ficção totalitária decreta que todo comércio deve ser do mesmo com o mesmo. No ódio do laço que o outro mantém com suas origens de língua e com suas modalidades de gozo, essa ficção totalitária não quer saber nada de um princípio de arresto. Pode-se resumir até o voto armado do desaparecimento desse chamado da estranheza que sustenta o estrangeiro. A ficção é então que o que é próprio do homem repousa e se reúne numa imagem unívoca, e que seria, em sua própria essência, localizada num lugar de geometria fechada e fixa: a Terra identitária e o solo onde vivem os senhores soberanos pelo sangue e pela categoria. Esse mito da inocência legítima a ser reencontrada e restaurada numa origem pura em que nunca o trabalho de divisão tivesse podido depositar sua obra simbólica se reativa pela violência política no momento em que a própria língua brinca cruelmente com as catástrofes das possibilidades de subjetivação e de imaginação, isto é, no momento em que um coletivo pode se sentir abandonado à própria sorte em relação à língua, como logrado, em excesso.

Porque é, também nesses tempos, que a língua encontra seus próprios limites de sua capacidade figurativa de criações mito-poéticas. A quem se dirige o sujeito? Como forjar em seus sistemas simbólicos a dimensão da alteridade, como dizer o elementar da troca: o sim e o não ao outro, quando as palavras que se empregam, a língua que se fala, não têm mais sua promessa de memória para nos oferecer, nem seu jogo de acolhimento de todo sentido novo? 
Hoje em dia a condição de errantes, as derivas, os exílios imóveis, não são mais fatos secundários ou excepcionais. Dentre os sofrimentos que podem levar qualquer um a encontrar oferta analítica e, portanto, um psicanalista, "modalidades subjetivas” impõem práticas originais. Essas modalidades foram pouco enumeradas no tempo de Freud, e no tempo de Lacan também. Foram mais indicadas pelos clínicos anglo-saxões com Winnicott e depois dele. Inconsistentes, não devem mais ser ouvidas como o psicanalista que faz as coisas pela rotina ouviria os sintomas clássicos que o recalcamento engendra e determina. Não se decifram como formações de compromisso, mas aparecem bem mais como tempos inacabados de orientação pela fantasia, à falta de inscrição do sujeito, à falta de amarração entre eu e corpo, entre palavra e língua.

Que podemos esperar de um olhar psicanalítico (não uma interpretação) sobre o laço social, a não ser que legitime uma questão e depois tente respondêla? Se o nosso texto parte de uma inquietação a propósito da ruína moderna da palavra, então o fio condutor que puxamos se resume, de maneira muito abrupta, na questão seguinte:

"Por que o homem com tanta frequência dá ao terror preferência sobre seu desejo?"

Rompendo com qualquer psicologização do fato social, o ensinamento freudiano aqui é cortado e proveitoso. Freud nunca afirmou que o recalcamento proviesse da repressão, nem que o mal-estar fosse o puro produto do recalcamento. Sobre isso é que, com Lacan também, é possível enfatizar que a gulodice evidenciada por uma das figuras do Supereu é efeito de estrutura. "Não efeito de civilização, mas sintoma na civilização”, precisava Lacan em 1974. Essa modalidade do Supereu, infinitamente paradoxal que liga ao mesmo tempo a injunção — portanto a separação — ao ideal de não alterização, seria essa instância particular que, como essência da compulsão, se exerceria no sujeito, quanto à captura de todos na linguagem.

Esse supereu, não consolador, dá acesso então à raiz da força da lei que reside além do princípio de prazer, quer dizer, além da satisfação que garante a estrita obediência à regra social. Irredutivelmente quanto ao comando, seja o comando sem linguagem, em todo caso sem discursividade. Todo o tempo que sua ordem é apanhada como puro comando, a lei entrançada ao terror arranca o sujeito à melancolia, mas ao custo não apenas de acomodar-se à pura destruição, mas de reclamá-la como destruição pura. Para dizer a verdade, a melancolização do laço social nunca pode ser observada como momento histórico estável. Ela se interpreta desde que se precipite sob uma forma aterrorizante do excesso: qual seja, a possibilidade estupefaciente, embriagante e inocentante (tudo isso vai junto), que tem um coletivo de se tornar amável, unificando-se sob o puro comando de gozar. Um comando puro desses é, em si mesmo, excesso versus 
destruição, e não esse excesso que cria a falta por onde se retoma o binômio alienação/separação.

Esse amor à Lei reduzida ao seu âmago, esse amor à dessubjetivação diante do imperativo superegoico, distingue bem o momento em que a neurose se destaca de qualquer civilização. Sociedade do espetáculo, como dizia alguém que nos deixou recentemente, G. E. Debord, mas é preciso ir além de uma sociologia, por mais que fosse ou revolucionária ou situacionista. A grande aposta continua sendo de compreender como deslocar a grande facilidade com que todos se sujeitam a ser tiranizados. Nossa modernidade ocidental é feita dessa maneira, que a despeito da (ou talvez graças à) proliferação de ideais virtuosos de universalização, a segregação é cada vez mais portadora de destruição. A evolução histórica com a qual estamos às voltas, faz com que uma espécie de universalismo crescente não impeça, mas antes que favoreça, o fato de que se marquem clivagens cada vez mais acentuadas. Segregação não somente entre grupos humanos, mas também, e especialmente, entre representações "oficiais” do sujeito e de seu nome e representações “destruídas”, traços, mais do que o significante, e em todo caso expulsos antes de ter podido ser constituídos em rede significante.

Minha hipótese é que essa deflagração, esse eclipse da genealogia das organizações e dos locais de leitura dos traços culturais, se constata ao vivo nos contextos coloniais ou pós-coloniais, mas coloca ainda o estatuto da subjetivação na modernidade cientista e técnica que o Ocidente liberalista idealiza.

Se é desse jeito, e se é o social que por sua constituição impele a esse gênero de abrasão, impele a acreditar na redenção (cuja forma moderna é a satisfação) pelo consumo de um objeto totalmente satisfatório, destinado a um indivíduo cada vez mais estetizado como unissexual e sem história, então a psicanálise e a antropologia se verão em pé de igualdade para pensar, se não para promover, aquilo que seria uma clínica e uma lógica da dignidade humana.

É falso pretender que a modernidade seja complexa, opaca, ou clamar que ela estaria ornada por uma aura de obscuridade e de mistério. A modernidade não é um acontecimento complexo. A modernidade continua sendo um problema, um lugar e um tempo a construir. Em sua crueldade e sua crueza, contemporâneas, ela não se obscureceu, nem tampouco se complexificou. Está tecnicizada, mas essas jogadas se tornaram de uma brutalidade e de uma evidência que cegam: guerra de culturas e guerra de mundos econômicos, liberalização quer dizer uniformização. Arrojando-se impetuosamente naquilo que faz a distância entre desejo e palavra, a política técnico-científica moderna se oferece para apresentar os objetos e os modos de vida que terminariam por reconciliar o sujeito com sua perda, denegando esta a título de uma lembrança ruim ou de um arcaísmo. Assassinato da narrativa, proliferação autossuficiente dos objetos e dos corpos entrançados numa satisfação alimentada no cadinho das imagens purulentas. 
E ficaríamos admirados de que as novas formas do sintoma ponham em jogo o corpo e o além da satisfação pulsional, e nos admiraríamos de que a relação com a origem não fosse uma relação de diálogo ou de polêmica, mas sim uma espécie de celebração sacrifical, ou autossacrifical!

Oferecer uma escuta às formas clínicas e sociais da morte na linguagem, oferecer um esforço de reunião crítica dos saberes pulverizados acerca do humano, propor uma investigação das formas da morte social, não são gestões estrangeiras e antagonistas.

Quem, hoje, é melancolicamente tido por indiferente, repudiado do acontecimento que faz com que seja proposta, se não imperativa, a injunção de beneficiar-se da origem?

Esse sujeito às voltas com a apatia contemporânea, com as consolações virtuais e consumistas do mal-estar, esse morno espectador dos esmagamentos subjetivos, esse desiludido que fica espiando, apanhado numa espera sem nenhum centro de gravidade, esse sujeito que tem direito de cidadania na modernidade. Ele pode não ser ainda um projeto, mas já é uma promessa. Sua vinda e sua complexidade a construir que são mais do que desejáveis, não se veem asperamente interrogadas por figuras epônimas da alteridade. Eis aí uma necessidade lógica e ética.

Recebido em 17/11/2008. Aprovado em 23/2/2009.

\section{REFERÊNCIASS}

ALTHABE, G. (2004) "Productions du social, tendances actuelles”. Psychologie Clinique, 16, "Anthropologie et clinique: recherches Ruptures des liens, cliniques des altérités” (sob a direção de DOUVILLE, O. e WACJMAN, C.). Paris: L'Harmattan, p.19-34.

AGAMBEN, G. (1997) Homo sacer, le pouvoir souverain et la vie nue, trad. Marlène Raiola. Paris: Seuil. (Col. L'Ordre philosophique).

ARENDT, A. (2002) Les origines du totalitarisme. Paris: Quarto Gallimard.

AUDISIO, M., CADORET, M., DOUVILlE, O., GOTMAN, A. (1996) Anthropologie et psychanalyse: une rencontre à construire. Journal des anthropologues, 64/65, p.127-142.

AUGE, M. (1997) La guerre des rêves. Exercices d'ethno-fiction. Paris: Seuil.

DOUVILLE, O. (1998) “L' 'identité/altérité' Fractures et montages. essai d'anthropologie clinique”, in KAËS, R. (ed.) Différence culturelle et souffrances de l'identité. Paris: Dunod.

. (1999) "Notes d'un clinicien sur les incidences subjectives de la grande précarité”. Psychologie Clinique n.vii, série, printemps, p.57-68. . (2000) “Des adolescents en errance de lien". L’Information Psychiatrique, n.1, jan, p.29-34. 
(2001) "Les exclusions psychiques du marché". Histoire et anthropologie, n.22, premier semestre, p.141-156.

FURTOS, J. (ed.) (2008). Les cliniques de la précarité, contexte social, psychopathologique et dispositifs, Issy-les-Moulineuax, Masson.

HOURS, B. e SELIM, M. (2003) “L'altération de l'altérité entre domination et marchandise", Psychologie Clinique, 16, Ruptures des liens, cliniques des altérités (sob a direção de DOUVILLE, O. e WACJMAN, C.). Paris: L'Harmattan, p.9-18.

Olivier Douville

douvilleolivier@noos.fr 